\title{
La Tilma del Tlatoani y su Simbolismo Sacro
}

\author{
María Guadalupe Buzo Flores \\ Facultad de Ciencias Políticas y Administración Pública-UAEM
}

Resumen: El trabajo que se presenta a continuación, tiene por objeto develar algunos de los posibles simbolismos contenidos en una tilma usada por gobernantes del altiplano central, fundamentalmente mexicas durante el posclásico tardío; en el entendido de que aquéllos representaron la legítima faceta de autoridad reconocida por su pueblo, así como rastrear la asociación y posibles relaciones simbólicas entre dicho poder y lo sagrado.

Abstract: The aim of this essay is to show some symbolic meanings contained on the cloak wore by Aztec emperor. The author places a close relation between power and sacred world of that people with the cloak as a symbol of emperor power and legitimacy.

\section{Algunas precisiones}

La historia de un grupo social se construye partiendo de documentos escritos, si existen; y también de objetos y de todo aquello que la sociedad de una época pone aparte, separa, todo eso que es producido por ella, no sólo a partir de su iconografía, sino que se extiende al universo de las imágenes mentales, que esa sociedad del pasado, de forma consciente o inconsciente, crea.

En toda cultura existen aspectos de representación que cobran vida de múltiples formas desde la arquitectura hasta el uso y diseño de indumentaria y ornato, y resultan por tanto útiles herramientas para la comprensión de un determinado momento histórico. Reconstituir alguno de los aspectos de la representación, entendido como producto del espíritu de una época, es acercarse a las pistas del pasado e intentar seguir los hilos que llevan de la forma representada a las pautas de conducta y praxis descubriendo el mundo simbólico subyacente, esa parte de la dimensión imaginaria que propicia el conocimiento del corazón de las sociedades.

Toda representación, todo hecho portador de significación participa de la dimensión simbólica al mismo tiempo que de la dimensión imaginaria. Todo proceso de significación está formado por imágenes, 
las cuales están allí para representar una cosa distinta de ellas mismas; por tanto tienen una función simbólica (González, 1995: 25).

Las significaciones imaginarias definen el ser de grupo, cómo se ve, cómo se reproduce, cómo se construye su modelo de mundo, es el sitio de elección de lo que cuenta para esa sociedad, de lo que queda incluido y lo que está fuera, de la forma de organizar el orden, los actos, los valores, etc. En pocas palabras, es ahí donde el hombre de esa sociedad encuentra la razón de su ser profundo que importa para la vida del grupo. Y no es de cualquier modo como puede expresarse; el sistema espacio-temporal en el cual el hombre se expresa implica un encarcelamiento de símbolos que conducen a significaciones imaginarias sólo posibles dentro de ese ámbito cultural y del que quedan excluidas, y por tanto sancionadas, otras posibilidades expresivas. Lo mismo puede decirse del valor del vestido y los accesorios que lo acompañan: "El adorno posee antes que todo un valor étnico" (Leroi-Gourhan, 1971: 339) que permite ubicar a los actores, aportando información de su papel social, de su función, etcétera.

En el estudio de distintas civilizaciones antiguas hay un factor que permanece constante, y la sociedad que nos ocupa no es la excepción: el móvil esencial de todos los actos, pensamientos y sentimientos es la convicción de que lo divino es inmanente a la naturaleza.

El material que nos ocupa pertenece a la cultura mexica del posclásico tardío asentada en el altiplano central, que fue una sociedad profundamente cargada de simbolismo en todos los aspectos de la vida. La existencia de este hombre transcurre en un universo conformado por un espacio que propicia la existencia, en tlaltícpac, esa dimensión horizontal que limitan los puntos cardinales y que está rodeada por una verticalidad compuesta por trece niveles celestiales hacia arriba, hacia el infinito, un mundo masculino que participa de la dualidad inherente al mundo mesoamericano en la que en cada nivel habita una pareja de deidades, a imagen de la concepción cósmica dual original; aunque "sólo nueve de esos cielos son de orden cósmico en tanto que los cuatro restantes pertenecen al dominio espacial del hombre" (Johansson, 1994: 92); y otra que se orienta hacia el mundo infraterrenal femenino que consta de otros nueve niveles. El espacio humano de la existencia, transcurre en ese mundo cíclico que se halla ubicado entre el cielo y la tierra, en el ámbito eidético de la imagen estructurante del árbol que funciona como eje del mundo (Johansson, 1994: 24; Séjourné, 1992). 
El mito da cuenta de la creación de ese espacio humano a partir de la intervención, bajo la forma de árboles, de Quetzalcóatl y Tezcatlipoca. Además, hay representaciones del árbol de la vida en códices como el Borgia o el Vindobonensis y podríamos pensar en la danza de los voladores, cuyo origen ritual lo asocia a deidades de la fertilidad y que expresa por medio del tronco de árbol, (al que trepan y del que se dejan caer los voladores) el elemento que liga el centro con el cielo y con la tierra, de cuya unión se adquiere la fuerza fertilizante que garantizará la sobrevivencia del grupo humano.

Los escenarios naturales como montes, cuevas, quebradas, bosques, llanos, caminos o encrucijadas, lagunas u ojos de agua sirven de escenario natural para las formas rituales. Eran objeto de culto y de una minuciosa observación que también llevaba a la interacción con el medio ambiente, por parte de una población que dependía de las adversidades del clima para el cumplimiento del ciclo agrícola donde la preocupación fundamental giraba en torno a la lluvia (Broda: 1991). En la elección de un lugar para la construcción de una ciudad se deja ver el sentido simbólico religioso que lleva implícito: el sitio elegido se encuentra ubicado en el centro del mundo, lugar al que confluyen en su eje el cielo, la tierra y el inframundo, representan la culminación arquitectónica del espacio ritual que imita la montaña y es coronada por el adoratorio del dios.

La coordinación que existía entre el tiempo y el espacio, en la cosmovisión mesoamericana, encontró su expresión en la arquitectura mediante la orientación de pirámides y sitios arqueológicos (Broda citado en Ponce de León, 1991: 443).

Otro tanto sucede con el trazado de la ciudad y la orientación que deberán tener los distintos templos, calzadas y edificios. Se trata de reproducir un microcosmos que converja en el eje del mundo y a partir del cual se garantice la armonía del universo, donde el hombre se sume a la dimensión cósmica y en el que no se deje de lado la inmanencia telúrica garantizada por la tierra. Hay que tener en mente que la arquitectura mesoamericana no es una arquitectura de interiores, sino que son los elementos arquitectónicos los que delimitan el espacio exterior, humanizándolo, domesticándolo y convirtiéndolo en un espacio simbólico: "podría decirse que sus grandes espacios abiertos, sus grandes plazas, crean lugares armónicos con la bóveda celeste; es 
decir, los espacios urbano-aquitectónicos enmarcan o se conjugan con los acontecimientos de su cosmovisión" (Ponce de León, 1991: 444).

\section{Evidencia textil}

Si entendemos por textil cualquier tipo de producto elaborado con fibras capaces de ser torcidas, retorcidas, lazadas, entrecruzadas, entretejidas y que a la vez sirvan de apoyo o soporte para recibir o contener otros materiales como tramas, cordeles, cordones, lazos, cuentas, cascabeles, caracoles, plumas, etc., hemos logrado acercarnos al concepto de tejido prehispánico.

El textil, por naturaleza, resulta un material perecedero y si a ello sumamos lo variable de las condiciones climatológicas del área mesoamericana que fluctúan anualmente entre un clima seco o parcialmente seco a condiciones de extrema humedad durante la temporada de lluvias, podemos concluir que una mínima parte de fragmentos ha sido la que se ha conservado y tal vez por eso su estudio resulte difícil de asir. No obstante, la habilidad manual que desarrollaron nuestros antepasados para la elaboración de hilos finos, cordeles y tejidos de diversas calidades, quede manifiesta de forma indirecta en los fragmentos de cerámica decorados con hilos y tejidos impresos como los procedentes del sitio de La Victoria, Guatemala, en su fase Ocós, reportado por Coe (1960), en el de Mayapán reportado por Mahler (1962), en los de Uaxactún, Guatemala, reportado por Kideer (1947) en Johnson, (1954: 139), por citar sólo algunos casos.

Hay evidencias de restos de una cápsula de algodón (Gossipium hirsutum L.) que fueron encontrados en el valle de Tehuacán, Puebla, fechados como anterior a 5000 a.C. En el mismo sitio hay fragmentos de tejido de cestería fechados entre 6000-4800 a.C., que aunque no se trata de textiles, puede tomarse como un antecedente. El fragmento textil más temprano proviene de la fase Santa María (900-200 a.C.) y fue elaborado con hilo de algodón con grado de torsión crepé (hilo con alto grado de torsión que va de 40 a 80 por pulgada). Tal vez el hallazgo más importante de este sitio, por su condición de preservación casi intacta, se refiera a las dos mantas mortuorias correspondientes a la fase Palo Blanco (200 a.C.- 700 d.C.) confeccionadas con hilos de una fibra distinta al algodón que tienen urdimbre de diferentes colores y grados de torsión de hilatura desde moderada hasta fuerte. La variedad de fibras usadas, de algodón o izote, la variedad de tipos de hilos, así como de grados de torsión y dirección del torcido durante la hilatura, 
del teñido en diversos colores como el café, el café rojizo, el gris, el negruzco o azuloso, etc. (Johnson, 1967) muestran de sobra el dominio y control del arte textil.

Las fibras eran extraídas de plantas; entre las más comunes estaban las provenientes del maguey o ixtle, de yuca o izote y de ortigas que eran utilizadas por la mayoría de la población para la confección de las prendas. Un caso aparte lo constituía el algodón que fue usado por personas de alto rango y que formaba parte del tributo en sus dos modalidades conocidas: el blanco o ichcatl y el de color pardo llamado coyoichcatl, literalmente algodón coyote. Y algunas prendas se decoraban con vellón de pelo de conejo (tochomitl) entretejido en el diseño o con plumas de una gran variedad de aves que también llegaban a Tenochtitlán en forma de tributo o por medio del comercio a largas distancias conducido por los pochtecas para ser empleadas por tejedoras y/o amantecas.

En el siguiente párrafo trataremos de resumir la diversidad tecnológica textil a la que había llegado la cultura náhuatl del posclásico:

Se tuvo conocimiento del tejido sencillo otafetán, de canasta y semicanasta, diseños de franjas de urdimbre, gasa, sarga o twill, brocado, tapiz o kelim, tejidos pintados a mano libre, telas estampadas en batik ; y aunque no existen restos arqueológicos del tipo de estampado conocido como plangi, anudado o tye and dye, podemos pensar por el tipo de diseño resultante -pequeños rombos coloreados en el centro-que también fue dominado; así parecen indicarlo algunos diseños de textiles que pueden observarse en la Matrícula de Tributos.

Y si lo anterior fuera poco para el lector, una mirada a la etnología ampliará nuestro panorama y nos permitirá comprender mejor el impacto visual de la forma, el diseño, el icono, el material, el colorido, la textura y el adorno que han dominado las tejedoras. Ellas son dadoras de vida que materializan los sueños, las ideas, las creencias, la naturaleza; en pocas palabras: la cultura de un pueblo cuyos diseños se pierden en la noche del tiempo. Así pues, el textil, ese frágil testigo de cada época, no pretende gozar de larga vida, ya que no añora el lugar de una pieza escultórica o cerámica, se sabe perecedero como las flores y las vidas humanas que los poetas de todas las épocas bien conocen. 


\section{Función económico-social del textil}

Para el estudio del atuendo mesoamericano no hace falta decir que casi nada se ha conservado y por tanto debe abordarse a partir de las representaciones en cerámica decorada, figurillas de barro, escultura, pintura mural o códices.

El atuendo común consistía en un maxtlatl o braguero y una tilma para los hombres ; y según se observa en distintos códices había una prenda que se colocaba alrededor de las caderas - pañete masculino-, de la que se sabe poco, y parece estar asociada en esas fuentes a músicos, guerreros, gobernantes y deidades.

El atuendo femenino consistía en un enredo o cueitl, a modo de falda, o bien su usaba un huipil. Y en algunas regiones se usó el quechquemitl; aunque en otras, sólo parece haber estado asociado a la indumentaria propia de las diosas.

Estas prendas fueron las mismas que usaban los nobles (pipiltin), sacerdotes y guerreros elaboradas de algodón -connotación de su estatus-y estaban ricamente decoradas si se las compara con las de los macehuales. Cierto tipo de diseños estaban relacionados con determinados usos rituales ; aunque cabe aclarar que la gran mayoría no han sido investigados y por lo tanto, no se ha podido establecer la correlación entre ellos, además que de algunos diseños se conocen únicamente los nombres y/o breves descripciones a partir de fuentes como los Primeros Memoriales, el Códice Florentino o la Historia general de las cosas de Nueva España de Sahagún, sin que haya podido determinarse por medio de fuentes alternativas que cuentan con el dato visual cuál es la correspondencia entre los nombres y los diseños.

Por otro lado, tenemos que existían algunas prendas específicas que estaban relacionadas con una jerarquía social; este es el caso de los xicolli, especie de camisa corta decorada en el extremo inferior y que fue una prenda ritual usada por los sacerdotes. Ya se comentó antes que el pañete femoral masculino se reservaba para los gobernantes, sacerdotes o deidades. Y eran comunes entre los guerreros unas

1 Para conocer más detalles sobre el tema, consultar Anawalt (1981) Indian clothing before Cortés: mesoamerican costumes from the codices, University of Oklahoma Press.. 
armaduras acolchadas (ichcahuipilli) que estaban rellenas de algodón y que cubrían totalmente el torso hasta la altura de la entrepierna; su eficacia resultaba tal que los mismos españoles la adoptaron en la primera etapa de la conquista. Algunos trajes especiales para los guerreros tenían distintas hechuras; los había de coyote (tozcoyotl), de ocelote (ocelotl), con remate de cabeza de Xólotl (cuaxolotl). Esta clase de atuendos han quedado registrados en la Matrícula de Tributos como pago de las provincias sometidas por los mexicas. Por último, otro atuendo particular fue el empleado en el juego de pelota que contaba con prendas protectoras de cabeza, de caderas, de antebrazos y guantes y que pueden apreciarse en distintas figurillas de barro procedentes de diversas regiones mesoamericanas.

Aunque no es el tema del artículo, no podemos dejar de mencionar la enorme cantidad de textiles que llegaban a Tenochtitlan como tributo y que han quedado constatados en la mencionada Matrícula de Tributos y una parte del Códice Mendocino -que la reproduce y completa en algunas láminas-y que constituyen por tanto la principal fuente para este tipo de investigación. ${ }^{2}$ Algunos de los principales puntos de discusión por los especialistas giran en torno a la extensión y control económico-político de los mexicas, cantidades y frecuencia en el pago de tributo, semejanzas y diferencias entre ambas fuentes (Barlow, 1949; Berdan, 1974, 1975), por ejemplo.

Los guerreros que hubieran destacado por haber capturado uno o varios enemigos eran retribuidos por el gobernante con tilmas de determinados diseños que a su vez habían sido recibidas como tributo según puede apreciarse en la lámina LXV del Códice Mendocino.

Es bien sabido que ciertas mantas llamadas quachtli servían para comerciar y cada una debe haber tenido un valor de cambio por granos de cacao como puede constatarse en el Pochtecayotl (Sahagún, 1961: 125).

Un último punto respecto a la función social y de prestigio, asociada a los textiles, es el hecho de la gran cantidad de menciones en diversas

2 En ese sentido, véase Mohar, Luz María (1976), El tributo mexica en el siglo XVI: análisis de dos fuentes pictóricas, México, Universidad Ibero Americana, tesis de licenciatura en antropología, y Mohar, Luz María (1990) La escritura en el México antiguo, México: Plaza y Valdés. 
fuentes, del textil considerado como un regalo preciado entre los habitantes de Mesoamérica. En este sentido, Cortés fue agasajado con textiles finos y variados enviados por Moctezuma, además del oro y joyas tan preciados por los españoles, en su recorrido hacia México. Del mismo privilegio gozaron los capitanes de Cortés y los soldados a quienes se les repartieron mantas además de oro (Díaz, 1992).

\section{Atuendo, simbolismo y religión}

En este panorama no resulta entonces extraño que los aspectos iconográficos relacionados con la indumentaria estuvieran dotados de simbolismo que los asociaba con acciones como la guerra (in mitl, in chimalli), con el poder del gobernante (tlatoani), con el ceremonial personificado en sacerdotes o víctimas propiciatorias que representaban alguna deidad o directamente a los distintos dioses, -recordemos que era frecuente vestir con atuendos precisos algunas representaciones escultóricas de deidades hechas de piedra que se adoraban en los templos en ciertas festividades del año-.

De hecho, es notorio que muchos de los diseños de la indumentaria debieron seguir ciertos esquemas precisos que los asociaban con cierto estamento social, como ya mencionamos. Sahagún en la Historia general de las cosas de Nueva España (libro VIII, capítulo VIII, 1992a) se ocupa de algunos de los nombres y descripción de los atavíos de los señores, haciendo la aclaración que todas las tilmas en cuestión "son sospechosas".

Después de una breve comparación de algunas tilmas tributadas provenientes de distintas regiones, puede observarse cierta semejanza entre algunos de los diseños descritos por Sahagún y los de la Matrícula de Tributos, por lo que procederemos a enunciar algunas: el caso de la ome tochtecomayo tilmatli cuyo diseño coincide -salvo por los colores usados de fondo- con la tilma chimalpapalotl itic tilmatli; o la tilma ecacozcatl que tiene semejanza con la iztac papatlauac yoan iztac tecciztli tilmatli. Y la ocelotilmatli yític ica ocelotl guarda semejanza con la manta de tigre del folio 6 verso del Códice Magliabechiano. Es posible que la "sospecha" de la que habla Sahagún pueda deberse a que algunas de estas tilmas hayan sido usadas para ciertas ceremonias, lo que podría rastrearse recurriendo a distintas fuentes y códices. Sin embargo, no es este el lugar para hacerlo ya que rebasaría con mucho nuestro objetivo. Baste por el momento haber mencionado algunos caminos posibles de investigación que no han sido abordados. 
La relación de indumentaria de los gobernantes y los nobles es aún más larga en el Códice Florentino y en los Primeros Memoriales en los que se describen además los atavíos propios para la danza. Huelga decir la intrínseca relación que mantuvo ésta con el ceremonial, citamos a Sahagún :

Lo tercero de que los señores tenían gran cuidado era de los areitos y bailes que usan para regocijar a todo el pueblo. Lo primero, dictaba el cantar que se había de decir, y mandaba a los cantores que le pusiesen en el tono que quería, y que le proveyesen muy bien... también mandaba los meneos que habia de haber en la danza, y los atavios y divisas con que se habian de componer los que danzaban... y señalaba el día del baile, para alguna fiesta señalada de los dioses. Para entonces él se componía con los aderezos que siguen: En la cabeza se ponía unas borlas hechas de pluma, y oro, atadas a los cabellos de la coronilla; poníase un bezote de oro, o de piedra preciosa; poníase también unas orejeras de oro en las orejas; poníase al cuello un collar de piedras preciosas de diversos géneros, poniase en las muñecas unas ajorcas, o sartalejos de piedras preciosas de chalchihuites o turquesas; también se ponía en los brazos, en los morcillos unas ajorcas de oro y un brazalete con un plumaje que sobrepujaba la cabeza, y otro plumaje en la mano; cubríase de mantas ricas, añudadas sobre el hombro; poníase unos ceñidores muy ricos, que ellos llaman maxtlatl. (1992a: 471)

Gestualidad, ritmo, alegoría de la voz en su máxima expresión quedaban de manifiesto en las celebraciones. El simbolismo adquiere así dimensiones insospechadas para nosotros, todo comunica: la voz, el timbre, la entonación, el gesto, el movimiento, el ritmo, la cadencia, la frecuencia, la proyección espacial del cuerpo, el espacio, el tiempo, la forma, la pintura facial y corporal, la indumentaria, el ornato corporal, el diseño de la decoración de cada prenda, el adorno de cada objeto incluido, el sonido, la música, la puesta en escena de cada instrumento, la melodía, la palabra, la proyección fonética, la incidencia de la luz natural o artificial, la interrelación de los asistentes como actores y/o espectadores; en fin, no hay nada que quede al azar, todo queda en su sitio, en donde debe y cuando debe estar ( $C f r$. Buzo, 1998).

Entre los escasos hallazgos de atuendos se encuentra un chaleco o pechero, que por haber estado confeccionado con placas de concha rosada e hileras de caracoles marinos y valvas sobrevivió hasta nuestros días localizado en el interior de una caja de adobe, en el centro y bajo el piso de un patio, del Palacio Quemado de Tula. Como sugieren Cobean y Estrada (1994) la ubicación de la ofrenda, la semejanza entre los hallazgos y las prendas que lucen los Atlantes, el resto de objetos contenidos en la ofrenda como ramas de coral y un 
elegante collar son un indicador del significado e importancia religiosa $\mathrm{y}$ denotan que pudo haber pertenecido a un rey tolteca, sacerdote principal o dirigente militar. La impactante presencia de elementos marinos procedentes tanto de la costa del Golfo de México como del Océano Pacífico y la semejanza entre este sistema de colocación de ofrendas y la seguida por los mexicas, parece relacionarla con el culto a la fertilidad y a deidades acuáticas. He aquí pues una relación tangible entre la indumentaria, el ceremonial, el simbolismo y lo sagrado. Sin embargo, no en todos los casos de estudio se corre con la suerte de contar con piezas arqueológicas y el trabajo debe seguir insospechados derroteros.

\section{La tilma xiuhtlalpilli del tlatoani y su probable simbolismo}

El diseño de tilma que nos ocupa fue usado por altos dignatarios; contiene pequeños rombos azules con el centro del mismo color que a su vez siguen un patrón con una greca escalonada según puede observarse en el folio 108 recto del Códice Ixtlilxóchitl fue usado por el noble Nezahualpilli y muestra estrecha semejanza con uno de los diseños de mantas recibidos como pago de tributo de acuerdo con la Matrícula de Tributos. Esta tilma también se encuentra representada en Primeros Memoriales, folio 55 vuelto, en el que se observa a un noble usándola, se le conoce con el nombre de xiuhtlatlpili y se le puede comparar con los nombres de las tilmas que proporciona el mismo Sahagún en el libro VIII del Códice Florentino donde se menciona con el nombre de xiuhtlalpilli tenyxio. Mientras que en el libro I del mismo códice se le da el nombre de xiuhtlalpilli yn tilma y es el dios Yiacatecutli el que la porta. El atuendo del dios fue descrito así:

Atavíos de Yacatecuhtli:

Muy aderezado su rostro,Motlatlatlalili in iaxayac,

(en forma de) columnas su tocado puesto en la frenteytemillo id est ixquatzon, con flecos de plumas de quetzal, y quetzalalpiay, sus orejeras de oro. Iteocuitlanacuch.

Su manto de malla azul,Xiuhtlapilli yn itilma, su maxtle precioso.Ytlazo maxtli.

Tiene puestas en sus piernas campanillas que son lo mismo que cascabeles, Tzitzilli, oyoalli, idem, contlaliticac icxic, sus sandalias principescas; éste es su calzado. Ytecac: in cactli. 
Su escudo con greca escalonada,Xicalcoliuhqui yn ichimal,

su bordón de viaje en una mano, o sea su bastón." Ytlaczaya, idest itopil yn imac ycac". (Sahagún, 1992b: 124-125)

Otras representaciones de gobernantes ataviados con ella provienen también del Códice Florentino y muestran el momento en el que le son presentadas las armas, divisas e insignias necesarias para la guerra y a punto de ser repartidas entre los nobles y los guerreros que partirían a la batalla (libro 8, cap. XVII, ilustración 77); o cuando el tlatoani repartía bienes entre los pobres, proporcionándoles vestido, alimento y lugar para dormir (libro 8, cap. XVII, ilustración 92). En el capítulo XX se narra la forma en que los nobles eran preparados para participar en las batallas y el tlatoani los recompensaba con diferentes artículos suntuarios en caso de distinguirse como hábiles guerreros (ilustración 99 y 100).

Bajo cualquiera de los nombres con los que aparece en las fuentes mencionadas, se hace alusión a una tilma color turquesa y cuya técnica de elaboración fue la de ataduras, pues siguiendo a Molina (1992) sabemos que xiuh proviene de xiuhtic, "color turquesado"; este es el adjetivo de xiuitl, "año, cometa, turquesa e yerua"; y tlalpili es "cosa atada o añudada"; tenyxio, que "tiene el borde adornado con ojos y se aplica a indumentaria con los bordes decorados". Por tanto, fue una tilma color turquesa confeccionada con las técnicas de reserva de jaspeado o plangi y de batik, ${ }^{3}$ siguiendo un patrón de greca escalonada en meandro con bordes decorados con greca escalonada en espiral.

Esta tilma se recibía como tributo proveniente de once regiones: Petlacalco, Acolmecatl, Quauhnahuac, Huaxtepec, Quauhtitlan, Axocopan, Atotonilco (de Pedraza), Hueypochtlan, Atotonilco (el Grande), Xillotepec y Quahuacan (Anawalt, 1990) distribuidas en los actuales estados de Hidalgo, Morelos, México y Distrito Federal. Salta a la vista la contigüidad geográfica de dichos pueblos tributarios, por lo que puede pensarse en las posibles razones en cuanto a la distribución y conocimiento tanto de la técnica requerida para la elaboración de dicha tilma, como por las razones para que fuera tributada. Una probable interpretación es que estas provincias formaban parte del imperio

3 Según mis propias apreciaciones y experiencia de tejedora y que confirma Anawalt, (1990). 
acolhua durante el siglo XIII y del imperio tepaneca en el XIV; y que ambos estuvieron contenidos dentro de lo que fue el imperio tolteca. La contigüidad geográfica y la pertenencia a una misma herencia cultural sugiere la posibilidad de que dicho diseño haya servido como emblema que reflejaba la noble descendencia de linaje de estas áreas. Esta hipótesis deberá ser confirmada por medio de un análisis más minucioso que permita comprobar a partir de qué momento los mexicas adoptaron la tilma como símbolo distintivo del tlatoani y por el momento escapa a la intención del presente trabajo (Buzo, 1998).

En cuanto al simbolismo de la tilma hay varios aspectos que pueden resultar significativos: en primer lugar, su confección implica un conocimiento técnico preciso de escasa distribución geográfica según parece, que podrá arrojar datos en torno a la legitimación mexica de su ascendencia tolteca. En segundo lugar, el color turquesa en sus diversas formas, ya fuera chalchihuite, pluma de quetzal o hierba añil, como en este caso, se relaciona con lo precioso. Por su parte, el diseño del interior de la prenda con grecas escalonadas con meandros aporta un significado que lo asocia con "lo de abajo", el movimiento del Sol durante la noche. Además, el diseño del borde de la prenda con grecas escalonadas en espiral queda relacionado con "lo de arriba", el movimiento del Sol durante el día.

Puesto que en la persona del gobernante se sintetizan aspectos culturales fuertemente ligados con la teatralización y ritualización necesarios para la sociedad que representa ; y si además entendemos el poder simbólico como un poder de construcción de la realidad y un orden gnoseológico, como afirma Bourdieu (1990) podremos desenmascarar cierto significado ligado al papel del soberano. Así pues, la idea de ataduras y ligaduras asociada además al juego visual de grecas escalonadas lo relacionan con el mundo cósmico, de forma que el significado del nombre que lleva la tilma, que traducimos como "tilma color turquesa de ligaduras y anudados" podría referirse a la relación de unión entre el soberano y el cosmos. Esto nos mostraría una forma de sacralización del poder en la persona del gobernante, como sostiene Balandier (1976: 117): "El poder se halla 'sacralizado' porque toda sociedad subraya su voluntad de eternidad y teme el retorno al caos como realización de su propia muerte". El hilo que ató la tilma durante su elaboración y teñido podría referirse a la vinculación de los estados de existencia entre sí y con su Principio, como sostiene Guénon (1988: 357): 
(...) y asi el hilo... puede replegarse sobre sí mismo formando entrelazamientos o nudos; $y$, en la estructura del conjunto, cada uno de esos nudos representa el punto en que actúan las fuerzas que determinan la condensación y la cohesión de un "agregado" correspondiente a tal o cual estado de manifestación, de modo que, podría decirse, ese nudo mantiene al ser en el estado de que se trata y su "solución" o acto de desatarlo entraña inmediatamente la muerte a tal estado...

La tilma contiene ambos simbolismos: el de atar y anudar el hilo replegándose sobre sí mismo y el de desatar y por tanto dar paso a una nueva manifestación de otro estado. Esto podría interpretarse como una necesidad ¿de incluir al tlatoani en ese Principio manifiesto del cosmos? ¿de abrirle paso a esa nueva posición existencial que debe representar frente a los hombres y a los dioses? Si esto fuera así, la interpretación podría ir más allá, siguiendo el mismo hilo conductor de Guénon en el sentido de que el tejido condensa el entrecruzamiento de "líneas de fuerza" contenidas en la urdimbre y la trama, representando la estructura del cosmos. ¿Encontramos entonces, en esta tilma una posible carga simbólica que implicaría que el soberano es la legítima persona, que como encarnación divina, puede atar y desatar el cosmos para dar lugar a una sociedad en la que se garantice el mantenimiento del orden como espejo del propio cosmos? De acuerdo con Balandier (1976: 44), los soberanos y su burocracia son los instrumentos de una acción política entendida como necesidad, para toda sociedad, de luchar contra la entropía que la amenaza con el desorden. Y aunque al hablar de simbolismos nos quede manifiesto, como sostiene Rodhe (1987), que el símbolo siempre será misterioso por más que se le explique; no por ello deja de ser válido intentar encontrar sus posibles significados. El nudo se relaciona con lo que ata y lo que liga, por ese doble significado que le es inherente. El estudio de los nudos liga consigo el de los hilos y las cuerdas que unen entre sí los mundos, la ligadura es lo que une, no sólo entre sí, sino también -repitámoslo-con su Principio mismo, de manera que, muy lejos de seguir siendo una traba, se convierte, al contrario, en el medio por el cual el ser puede alcanzar efectivamente su Principio, y en la misma vía que lo conduce a esa meta. En tal caso el hilo o la cuerda tiene un valor propiamente “axial” (Guénon, 1988: 359).

Pero la ligadura también puede ser considerada como lo que ata; y el nudo, lo que hace de la ligadura una traba, lo que fija al ser en tal o cual estado. Para el mundo mesoamericano el nudo está presente en la representación de los códices; y es posible encontrar ese doble simbolismo: se liga el destino de los hombres como cuando se atan las 
puntas de las prendas de los futuros desposados, Códice Mendocino lámina 62; en el Códice Magliabechi folio 5 recto, se muestra una manta de ataduras que estuvo relacionada con algún ritual; en el folio 38 recto del mismo códice, en la fiesta Hueymiccailhuitl en honor a Huehueteotl se ve cómo unos personajes están por subir por una cuerda atada a un árbol sobre el que está sentado otro individuo, la cuerda podría interpretarse como la ligadura o unión al eje o centro del mundo que simboliza el árbol. La atadura de los años o xiuhmolipilli que acontecía cada cincuenta y dos años era una forma de ligar el tiempo cósmico; también se usaban cuerdas para atar a los señores o principales cuando morían, se les acomodaba en cuclillas y envolvía en mantas para luego atarlos antes de ser cremados (véase Códice Magliabechi, folio 66 recto y 67 recto; Códice Florentino, libro 3, cap. 1 apéndice, ilustración 15 y 16); lo mismo sucedía con los mercaderes y los mancebos muertos (ver folio 68 recto y 69 recto respectivamente). Por otra parte, las ofrendas de leña presentadas a los dioses que aparecen en el Códice Fejérváry-Meyer también se encuentran atadas de forma simbólica. Los guerreros y muchos dioses llevan atados a brazos y piernas cintas anudadas con las que quedan ligados sus destinos. Y las tilmas con las que se representa a los varones del telpochcalli son de fibra de maguey anudado. (Códice Florentino, libro 3 , apéndice cap. V, ilustración 18)

La idea simbólica de atadura del nudo y la cuerda la tenemos en la atadura de los cautivos, como en el Tlacaxipeualistli, Códice Magliabechi folio 30 recto, tal vez simbolizando que se ha atado su destino al de la deidad que encarnan. Y la cuerda con la que se da castigo a los malhechores comunes también ata su destino a una muerte por ahorcamiento por haber transgredido las normas, o bien, se simbolizan con las manos atadas para recibir otro tipo de castigo. Los nobles o guerreros transgresores también recibían castigo y son representados de manera similar. (Códice Florentino, libro 8, cap. XIV, ilustración 66 y 68)

El simbolismo de la cuerda y el nudo, y de las tilmas anudadas, está asociado con el poder y su aspecto sacro, y se legitima simbólicamente con el orden cósmico que encarna, garantiza y representa bajo ese signo distintivo que lo hace inconfundible. Pero el significado rebasa la propia legitimación y también expresa, como sostiene Balandier $(1976,47)$, la coerción ejercida sobre el individuo como puede 
observarse en el simbolismo de las cuerdas que significan el castigo a los que violan las normas establecidas socialmente.

El poder y los símbolos que lo acompañan confieren así a la sociedad los medios para afirmar su cohesión interna y de expresar su "personalidad", los medios para situarse o protegerse frente a lo que le es extraño. F. X. Sutton, (citado por Balandier, 1976: 44-45) en su estudio de las "representaciones políticas", subraya la trascendencia de los símbolos que aseguran la diferenciación en relación con el exterior, y también la de los grupos y los individuos representativos.

De hecho, la noción de soberano ligador y los mitos y ritos centrados sobre la "ligazón" son propios del sistema religioso indoeuropeo estudiado por el propio Guénon y por Eliade (1992). Éste ha investigado a Varuna, deidad hindú que está representada con una cuerda en la mano, cuyas ligaduras son mágicas, es un dios solar y al mismo tiempo uránico; y encuentra que este simbolismo tiene varios paralelos etnográficos entre iraníes, chinos, germánicos, melanesios, semitas, etc. y menciona cómo la magia de los nudos cumple una doble función: nociva cuando se usa frente a adversarios y benéfica cuando se aplica como protección. Sin embargo, al hacer mención de un simbolismo histórico propio del mundo indoeuropeo, no pretendemos trasladar mecánicamente dichos conceptos al mundo mesoamericano, sino mostrar un posible camino de investigación por el cual transitar cuidadosamente que permita arrojar nueva luz.

De lo anterior podríamos destacar dos puntos: primero, la tilma color turquesa de ligaduras y anudados estuvo asociada a altos dignatarios del altiplano central en el posclásico tardío, y su probable simbolismo contiene elementos que parecen asociar al soberano como legítimo representante de los dioses y garante del mantenimiento del orden cósmico. Y segundo, dejamos tendidos nuevos hilos para un futuro tejido en el sentido de una investigación que defina el momento en que dicha tilma fue incorporada al sentido ritual que envuelve la persona del tlatoani; que aborde de manera más detallada el simbolismo de ligaduras y nudos; y que establezca las razones y relaciones por las que Yacatecutli, deidad de los pochtecas, es representado ataviado con esa misma tilma.

Parafraseando a Eliade (1992: 126) opinamos:

Sea lo que fuere de estos puntos de vista generales, es probable que el complejo mágico-religioso de la "ligazón" corresponda a un 
arquetipo o a una constelación de arquetipos -hemos señalado algunos: el tejido del cosmos, el hilo del destino humano, el laberinto, la cadena de la existencia-. La ambivalencia y la heterogeneidad de los motivos de la "ligazón" y de los nudos, y también de la "liberación de las ligaduras",confirman la multiplicidad y diversidad de los planos sobre los que se "realizan" estos arquetipos.

\section{Consideraciones finales}

El camino elegido para esta investigación muestra, de forma breve, que un elemento de la indumentaria de un grupo humano y una época puede servir de pretexto para adentrarse en el mundo del que surge, que le da forma, que lo instaura como válido y le infunde sentido. Con mayor razón si el momento elegido pertenece al pasado remoto en el que las condiciones de vida se entrelazan y entrecruzan de tal manera que cada objeto, cada acto, cada sujeto, cada capa social se interrelaciona con todos los demás elementos de la cultura de la que es producto.

El hilo conductor está tendido, la urdimbre colocada, resta abordar el detallado trabajo de continuar tejiendo la trama e ir entretejiendo los puntos de ligadura que permitan intersectar adecuadamente la urdimbre. Somos conscientes de que toda reconstrucción e interpretación resultan necesariamente incompletas, por tanto, la intención no es agotar aquí el tema, sino plantear un posible enfoque que permita un acercamiento y un mayor conocimiento de esos hombres que con su hacer cotidiano vivieron y sintieron de forma tal vez mal comprendida por nosotros, hombres de otra época, con otra carga simbólica y distinta imagen y visión del mundo.

Concluyamos con lo más representativo del planteamiento y las preguntas pertinentes para cada punto: la tilma xiuhtlalpilli que nos ocupa fue uno de los atuendos propios de altos dignatarios; se hallan varias representaciones en códices y quienes la portan aluden al tlatoani. Habrá que continuar transitando por este camino para intentar responder desde cuándo los tlatoani usaron la prenda, por qué se incorpora e incluye en el Códice Florentino al momento de representar a los gobernantes mexicas. Y por qué en ciertos actos los tlatoani están utilizándola.

En uno de los códices el portador ha sido identificado como Nezahualpilli, descendiente de Nezahualcóyotl, gobernante de 
Texcoco. La pregunta obligada aquí será intentar asociar su atuendo y su alto rango con algún ritual, tal vez.

La tilma forma parte del atavío de una deidad de los pochtecas, ¿Qué relación puede tener el ritual en honor a Yiacatecutili con la clase en el poder ? ¿Qué relación se había establecido entre los dos grupos sociales?

Formó parte del tributo de una restringida región que había pertenecido al antiguo imperio tolteca, la interpretación puede relacionarse con la posibilidad de legitimación de los mexicas como descendientes de aquel imperio.

El diseño de la tilma la asocia con elementos celestes y en ella convergen los dos principios del movimiento del Sol; uno, que se relaciona con el movimiento diurno, con lo de arriba; y otro, que lo relaciona con el movimiento nocturno, con lo de abajo. ¿Porqué convergen esos principios de la cosmovisión en esta tilma del tlatoani? Probablemente por su función social de gobernante. Esta idea queda reforzada por la forma de elaboración del diseño, sus ataduras y ligaduras que podrían referirse a la vinculación de los estados de existencia que debía garantizar el tlatoani gracias a ese doble vínculo del nudo que enlaza y liga los mundos cósmico y humano y que por otra parte ata y puede resultar nocivo frente a "otros".

\section{Bibliografía}

Anawalt, Patricia (1981), Indian clothing before Cortés : mesoamerican costumes from the codices, University of Oklahoma Press.

(1990), “The emperor's cloak: aztec pomp, toltec circumstances", en American Antiquity, vol. 55, núm 22.

Balandier, Georges (1976), Antropología política, Barcelona: Alianza editorial.

Barlow, Robert (1949), The extent of the empire of the Culhua Mexica, Ibero Americana, vol.28, Berkeley: University of California.

Berdan, Frances (1974), "A comparative analysis of Aztec tribute documents", en XLI International Congress of Americanists, vol. II, México.

(1975), Trade tribute and market in the Aztec empire, University Microfilms International, Austin: The University of Texas,

Beyer, Hermann (1919-27), "El origen, desarrollo y significado de la greca escalonada", en EI México antiguo, t. II, núm. 3 y 4, México.

Bourdieu, Pierre (1990), Sociología y cultura, México: CONACULTA.

Broda, Johanna (1991), "Cosmovisión y observación de la naturaleza : el ejemplo del culto de los cerros en Mesoamérica", en Arqueoastronomía y etnoastronomía en Mesoamérica, México: Instituto de Investigaciones Históricas, UNAM. 
Buzo, Ma. Guadalupe (1998) : "Reflexiones sobre la gestualidad dancística", en Danzas tradicionales ¿actualidad u obsolescencia ?,México: UAEM.

Cobean, Robert y Elba Estrada (1994), "Ofrendas toltecas en el Palacio Quemado de Tula", en Arqueología Mexicana, v. I, núm. 6, México: Editorial Raíces.

Coe, Michael (1960), "Archaeological linkages with north and south America at La Victoria, Guatemala", en American Anthropologist, v. 62, núm. 3.

Castro, Ma. Guadalupe (1994), "La danza en el norte de Veracruz", en Arqueología Mexicana, vol. I, núm. 5, México: Editorial Raíces.

Códice Magliabechiano (1903), Introduction and commentary Nuttall,, Berkeley: University of California Press.

Códice Matrícula de Tributos (1991), Secretaría de Hacienda y Crédito Público, México.

Códice Fejérváry-Meyer (1964), en Antigüedades de México, recopilación de lord Kingsborough, Secretaría de Hacienda y Crédito Público, México.

Códice Florentino (1950), Translated Anderson \& Dibble, University of Utah, Santa Fe.

Díaz del Castillo, Bernal (1992), Historia de la conquista de Nueva España, México: Editorial Porrúa.

Eliade, Mircea (1992), Imágenes y símbolos, España: Editorial Taurus Humanidades.

González, César (1995), A lo invisible por lo visible, imágenes del occidente medieval, México: Instituto de Investigaciones Filológicas, UNAM.

Guénon, René (1988), Símbolos fundamentales de la ciencia sagrada, Buenos Aires: Eudeba.

Johnson, Irmgard (1954), "Chiptic cave textiles from Chiapas, México”, en Extrait du Journal de la société des Americanistes, t. XLIII Paris: Nouvelle Série. Texas Press.

(1967), “Textiles”, en The prehistory of Tehuacan valley, vol.2. , Austin: University of

Leroi-Gourhan, André (1971), El gesto y la palabra, Universidad Central de Venezuela, Venezuela Ediciones de la Biblioteca.

Mahler, Joy (1962), Textiles and textile impressions, Mayapán, Yuc. México, Washington.

Mohar, Luz María (1976), El tributo mexica en el siglo XVI : análisis de dos fuentes pictóricas, México, Universidad Ibero Americana, tesis de licenciatura en antropología.

(1990), La escritura en el México antiguo, México: Plaza y Valdés.

Molina, Fray Alonso de (1992), Vocabulario en lengua castellana y mexicana, México: Editorial Porrúa.

Ponce de León, Arturo (1991), "Propiedades geométrico-astronómicas en la arquitectura prehispánica", en Arqueoastronomía y etnoastronomía en Mesoamérica, México: Instituto de Investigaciones Históricas, UNAM.

Rodhe, Teresa (1987), “Los nudos: apuntes para una investigación iconográfica”, en Historia de la religión en Mesoamérica y área afines, I Coloquio, México: UNAM.

Sahagún, fray Bernardino de (1961),Textos de los informantes de Sahagún :3 Pochtecayotl (arte de traficar) Vida económica de Tenochtitlan, Paleografía, versión, introducción y apéndices de Ángel Ma. Garibay, México: Instituto de Historia, UNAM. INAH, SEP.

(1974), Primeros memoriales, (tr. Wibgberto Jiménez), col. Científica, México:

(1992 a), Historia general de las cosas de Nueva España, México: Editorial Porrúa. 
(1992 b), Textos de los informantes de Sahagún : 1 Ritos, sacerdotes y atavíos de los dioses,( Introducción, paleografía, versión y notas de Miguel León-Portilla), México: Instituto de Investigaciones Históricas, UNAM.

Séjourné, Laurette (1992), Pensamiento y religión en el México antiguo, col. Lecturas mexicanas, núm 30, México: Cultura SEP.

Vega, Constanza (1991), "El curso del sol según los glifos de la cerámica azteca tardía", en Arqueoastronomía y etnoastronomía en Mesoamérica, México: Instituto de Investigaciones Históricas, UNAM. 